\title{
Modelling and performance of heat pipes with long evaporator sections
}

\author{
Wessel W. Wits ${ }^{1} \cdot$ Gert Jan te Riele $^{2}$
}

Received: 27 August 2016 / Accepted: 30 March 2017 / Published online: 27 April 2017

(C) The Author(s) 2017. This article is an open access publication

\begin{abstract}
This paper presents a planar cooling strategy for advanced electronic applications using heat pipe technology. The principle idea is to use an array of relatively long heat pipes, whereby heat is disposed to a long section of the pipes. The proposed design uses $1 \mathrm{~m}$ long heat pipes and top cooling through a fan-based heat sink. Successful heat pipe operation and experimental performances are determined for seven heating configurations, considering active bottom, middle and top sections, and four orientation angles $\left(0^{\circ}, 30^{\circ}, 60^{\circ}\right.$ and $\left.90^{\circ}\right)$. For all heating sections active, the heat pipe oriented vertically in an evaporatordown mode and a power input of $150 \mathrm{~W}$, the overall thermal resistance was $0.014 \mathrm{~K} / \mathrm{W}$ at a thermal gradient of $2.1 \mathrm{~K}$ and an average operating temperature of $50.7^{\circ} \mathrm{C}$. Vertical operation showed best results, as can be expected; horizontally the heat pipe could not be tested up to the power limit and dry-out occurred between 20 and $80 \mathrm{~W}$ depending on the heating configuration. Heating configurations without the bottom section active demonstrated a dynamic start-up effect, caused by heat conduction towards the liquid pool and thereafter batch-wise introducing the working fluid into the two-phase cycle. By analysing the heat pipe limitations for the intended operating conditions, a suitable heat pipe geometry was chosen. To predict the thermal performance a
\end{abstract}

Electronic supplementary material The online version of this article (doi:10.1007/s00231-017-2040-5) contains supplementary material, which is available to authorized users.

Wessel W. Wits

w.w.wits@utwente.nl

1 Faculty of Engineering Technology, University of Twente, P.O. Box 217, 7500 AE Enschede, The Netherlands

2 Thales Nederland B.V., P.O. Box 42, 7550 GD Hengelo, The Netherlands thermal model using a resistance network was created. The model compares well with the measurement data, especially for higher input powers. Finally, the thermal model is used for the design of a $1 \mathrm{~kW}$ planar system-level electronics cooling infrastructure featuring six $1 \mathrm{~m}$ heat pipes in parallel having a long ( $75 \%)$ evaporator section.

Keywords Heat pipes $\cdot$ Planar cooling $\cdot$ System-level electronics cooling $\cdot$ Long evaporator section $\cdot$ Evaporatordown mode $\cdot$ Dynamic start-up response

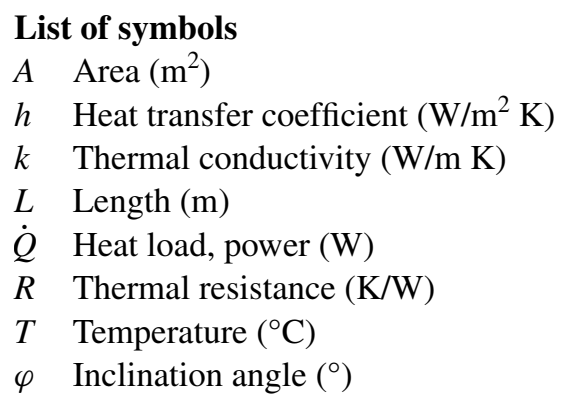

\section{Introduction}

In the application of planar electronic systems, such as Active Electronically Scanned Arrays (AESAs), heat is generated across the entire surface. This plane must be cooled uniformly to avoid signal distortion and excessive mechanical loads on the connections. However, with the advancements in (power) electronics and the demanded increase in performance, thermal power densities continuously increase. Conventional cooling methods (i.e. conduction and convection) do not suffice anymore, leading to overheating and undesirable heat concentrations. As a counter measure, this research explores the application of 
two-phase heat transfer mechanisms for planar cooling at the system level.

Two-phase heat transfer systems are well known for their effective heat transfer capabilities. They offer high thermal coefficients for heat transport while having a relatively low temperature gradient. They have advantages in terms of size and weight, and they require no external power, moving parts or pump making them a reliable alternative for a heat transport device $[1,2]$.

Although many variants exist (e.g. heat pipe, thermosyphon, loop heat pipe, pulsating heat pipe, etc.) the basic principle is that a working fluid evaporates from the high temperature section (i.e. the evaporator section) thereby driving the device due to the local increased vapour pressure [3]. For planar applications in many studies, the focus lies either on flattening (or embedding) a traditional heat pipe, to increase the width and contact area, or on designing a flat-shaped heat pipe [4, 5]. Lin and Wong [6] presented empirical rules of thumb to estimate the performance degradation of flattened heat pipes. Semenov [7] presented a planar heat pipe having a square footprint of $10 \times 10 \mathrm{~cm}^{2}$, in which the vapour space was maximized while providing sufficient support to the heat pipe structure. Similarly, Dillig et al. [8] integrated a planar heat pipe into a solid oxide cell stack, in which an internal heat pipe structure that allows for sideways thermal transport was milled. Also, Schreiber et al. [9], considered a counter-current thermosyphon with cascading pools for planar cooling applications.

\subsection{Goal and outline}

Planar or flat plate heat pipes, in which the emphasis is on heat spreading and temperature flattening rather than heat transport, are also coined vapour chambers [10]. For the intended application, the heat pipes need to be relatively long, compared to state-of-the-art electronics cooling approaches. The heat pipes are used for planar cooling but not in the aforementioned sense. In this study, the focus is not on (increasing) the evaporator size in the radial, sideways direction, but rather on the evaporator size in axial, lengthwise direction. This is also where the novelty of this study lies. $75 \%$ of a $1 \mathrm{~m}$ heat pipe will be used in mixed heating configurations to extract heat from a planar surface. Next to the well-known criteria for heat pipe design, this type of configuration may also introduces a new dynamic start-up effect in which working fluid is put into the twophase cycle in a batch-wise manner.

The main goal of this research is to understand the use of a long $1 \mathrm{~m}$ heat pipe for the thermal management of planar structures. This involves modelling the thermal performance of a single heat pipe in order to predict the steady state temperatures across the heat pipe in various conditions. This is discussed in Sect. 2. Sections 3, and 4 present the experimental setup and results, respectively, on a single $1 \mathrm{~m}$ heat pipe. Heat pipe performances with different evaporator section configurations and different inclination angles are the two main points of interest. Section 5 discusses the thermal model validation, after which in Sect. 6 the final design for a planar cooling application is presented.

\section{Heat pipe modeling}

\subsection{Heat pipe limitations}

During operation, heat pipes may encounter various limitations. Common limitations that are well documented in literature $[2,3,11,12]$ are: viscous limit, sonic limit, entrainment limit, boiling limit and capillary limit. In the application of electronics cooling the most common limitation is the capillary limit [13]. This limit is reached when the wick structure cannot return sufficient working fluid to the evaporator region.

Figure 1 graphically shows the implications of various limits for a $1 \mathrm{~m}$ long heat pipe with a $12 \mathrm{~mm}$ diameter and a grooved wick structure. The container is made of copper and the working fluid is water. In this analysis, the heat pipe is vertically oriented with top cooling (i.e. condenser section above). The figure shows the influence of three evaporator lengths $0.25,0.50$ and $0.75 \mathrm{~m}$ with the dashdotted, dashed and solid lines, respectively measured from the bottom side. The evaporator length has no influence on the sonic limit (green) and entrainment limit (red). All heat pipe limits are modelled according to Faghri [3].

For the intended working condition around $200 \mathrm{~W}$ power dissipation and an evaporator temperature around $40{ }^{\circ} \mathrm{C}$, the figure shows no serious limitations. For inclination angles other than vertical, the capillary limit (black) drops and becomes more dominant. For the intended working condition it was determined that a minimum $5^{\circ}$ angle with respect to horizontal should be maintained.

\subsection{Heat pipe thermal model}

To guarantee continuous heat pipe operation, it is vital to analyse the operating conditions (e.g. heat load, ambient temperature and orientation) and the chosen geometry of the heat pipe, and confirm that the heat pipe always remains within its limits. As a worst-case scenario check, this is imperative and for the selection of the heat pipe of this study this was ascertained following the procedure of Sect. 2.1; however, for the design of a planar cooling application more details about the thermal behaviour, especially in steady state operation, is required. Hence, for this study the selected heat pipe 
Fig. 1 Heat pipe limitations for a $1 \mathrm{~m}$ heat pipe $\varnothing 12 \mathrm{~mm}$ with $0.25,0.5$ and $0.75 \mathrm{~m}$ evaporator sections

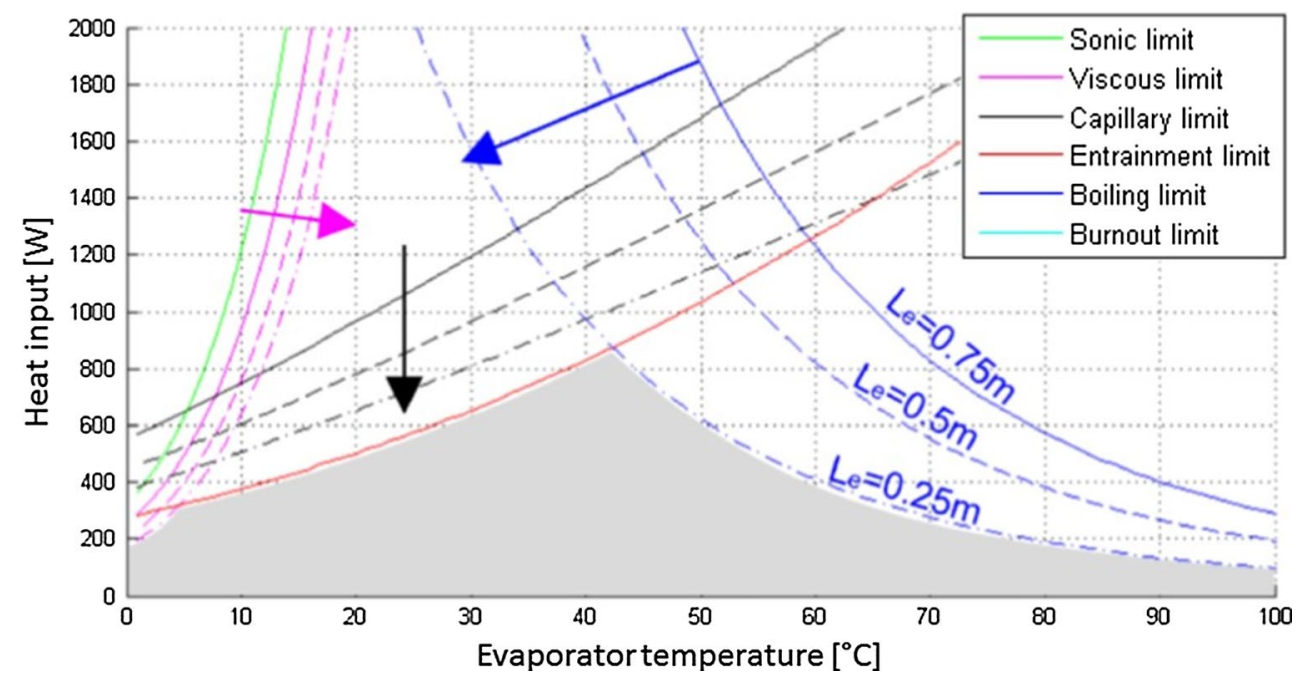

is modelled according to a thermal resistance network. Reay et al. [14] in 2006 presented an extensive resistance scheme, in which every aspect of the heat flow was taken into account. Their scheme consisted of ten thermal resistances arranged in parallel-series combination. Commonly three longitudinal resistances acting in parallel: wall conduction, wick conduction and axial vapour flow pressure losses. For this study, only the latter is taken into account, as for relatively long heat pipes the longitudinal wall and wick conduction effects are negligible [15]. This leads to a simplified resistance network, as visualized in Fig. 2, in which:

$\mathrm{R}_{1}$ : Condenser wall conduction.

$\mathrm{R}_{2}$ : Condenser wick conduction.

$\mathrm{R}_{3}$ : Resistance to condensation.

$\mathrm{R}_{4}$ : Frictional pressure losses.

$\mathrm{R}_{5}$ : Resistance to evaporation.

$\mathrm{R}_{6}$ : Evaporator (saturated) wick conduction.

$\mathrm{R}_{7}$ : Evaporator wall conduction.

As the simplified network has a serial layout, the total thermal resistance is modelled as the sum of all:

$R_{t}=\sum_{i=1}^{7} R_{i}=\frac{T_{8}-T_{1}}{\dot{Q}}$

where $T$ and $\dot{Q}$ represent temperature and heat load (power), respectively.

Heat transfer through a grooved wick can be modelled using an effective conductivity based on the wick permeability. Faghri [3] describes the heat flow through two parallel paths: (1) through the liquid and (2) through the fins, as shown in the insert (Fig. 2). Due to the relatively high conductivity of the copper heat pipe container, $k_{s}$, compared to the working fluid, $k_{l}$, the latter is neglected for determining the effective condenser conductivity:

$k_{e f f, c}=\frac{k_{s} F_{W}}{G_{W}+F_{W}}$

where $F_{W}$ and $G_{W}$ represent the fin width and groove width, respectively. To model the condenser heat transfer coefficient, $\bar{h}_{c}$, a saturated wick and laminar liquid filmwise condensation according to Nusselt [16] is assumed:

$\bar{h}_{c}=0.943\left(\frac{g \rho_{l}\left(\rho_{l}-\rho_{v}\right) H_{f g} k_{l}^{3}}{\mu_{l}\left(T_{4}-T_{3}\right) L_{c}}\right)^{1 / 4}$

where $\rho$ and $\mu$ represent working fluid density and viscosity, respectively, $H_{f g}$ is the latent heat of vaporization, $L_{c}$ is the condenser length, and $g$ is the gravitational constant. $T_{3}$ and $T_{4}$ correspond with the local temperatures of Fig. 2.

For the effective evaporator conductivity, the influence of the working fluid residing in the wick structure cannot be neglected and heat transfer at the fin corner and liquid film is modelled according to Chi [11]:

$k_{e f f, e}=\frac{F_{W} k_{l} k_{s} G_{H}+G_{W} k_{l}\left(0.185 F_{W} k_{s}+G_{H} k_{l}\right)}{\left(G_{W}+F_{W}\right)\left(0.185 F_{W} k_{s}+G_{H} k_{l}\right)}$

where $G_{H}$ represents the groove height. Note that Eq. (4) also account for the liquid evaporation. The groove and fin geometry is also visualized in Fig. 2. The effective thermal path in case of the evaporator is also highlighted.

Using the effective conductivities and condenser heat transfer coefficient, the condenser and evaporator resistances can be determined following the heat pipe geometry according to:

$R_{i}=\frac{L_{i}}{k_{i} A_{i}}$ 
Fig. 2 Simplified heat pipe thermal resistance network. The inserts shows the groove and fin geometry for modelling the effective conductivity of the condenser and evaporator sections, respectively

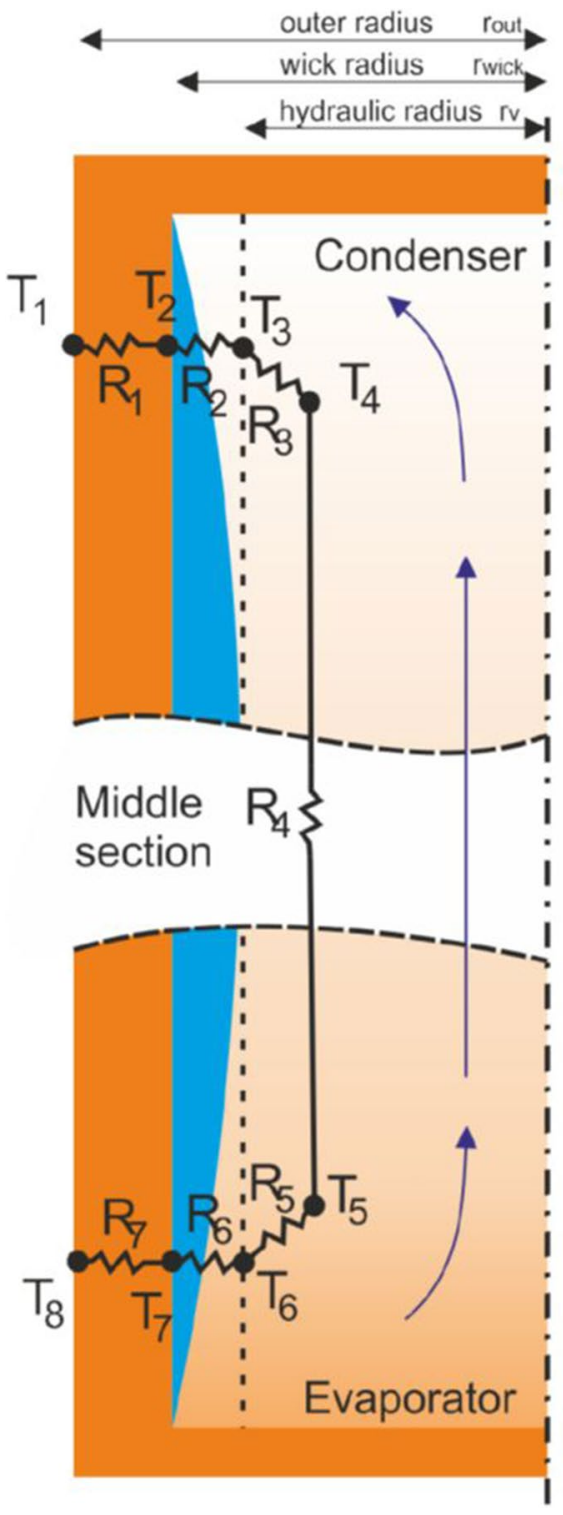

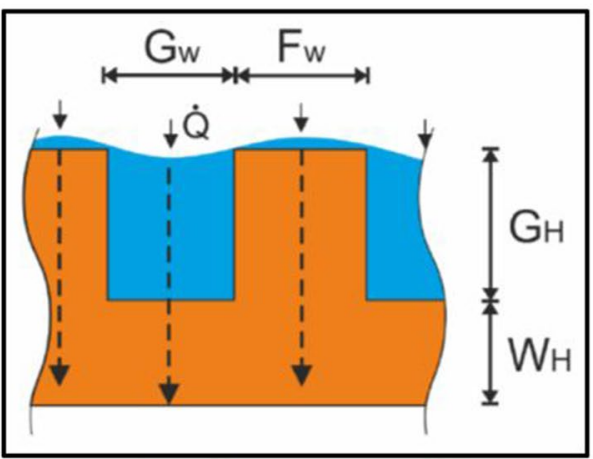

Condenser model

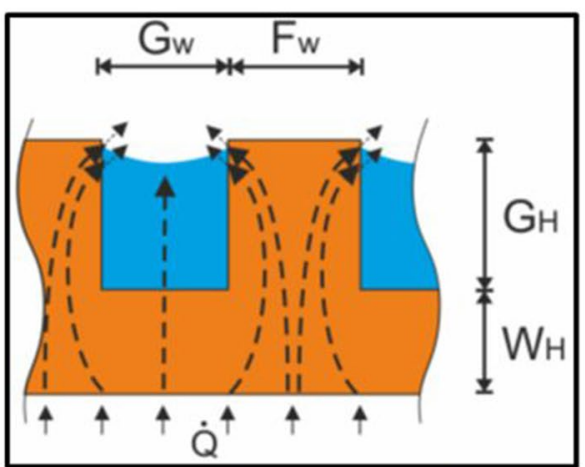

Evaporator model
$R_{i}=\frac{1}{h_{i} A_{i}}$

where Eq. (5) is used for the conductive paths and Eq. (6) is used for the convective paths.

Finally, the thermal resistance due to frictional pressure losses in the vapour flow must be modelled. For this the Hagen-Poiseuille [16] equation is used:

$\Delta P_{v}=\rho_{v} V_{v}^{2}+\frac{8 \mu_{v} \dot{m} L_{e f f}}{\rho_{v} \pi r_{v}^{4}}$

where $V_{v}$ and $\dot{m}$ represent vapour velocity and vapour mass flow, respectively, and $L_{e f f}$ and $r_{v}$ represent the effective heat pipe length and vapour cross-section radius, respectively.
Laminar flow and no pressure recovery in the condenser section are assumed in Eq. (7). Using the equation of state the temperature drop, and thus resistance, can be determined from the pressure drop.

\section{Experimental setup}

For the experimental validation, the $1 \mathrm{~m}$ long heat pipe with an external diameter of $12 \mathrm{~mm}$ is sandwiched between aluminium plates, as illustrated in Fig. 3a. The evaporator section consists of three separate $0.25 \mathrm{~m} \mathrm{sec}$ tions denoted bottom (B), middle (M) and top (T). Each section is thermally isolated except for the heat pipe itself that runs through the entire assembly. As heat pipes 


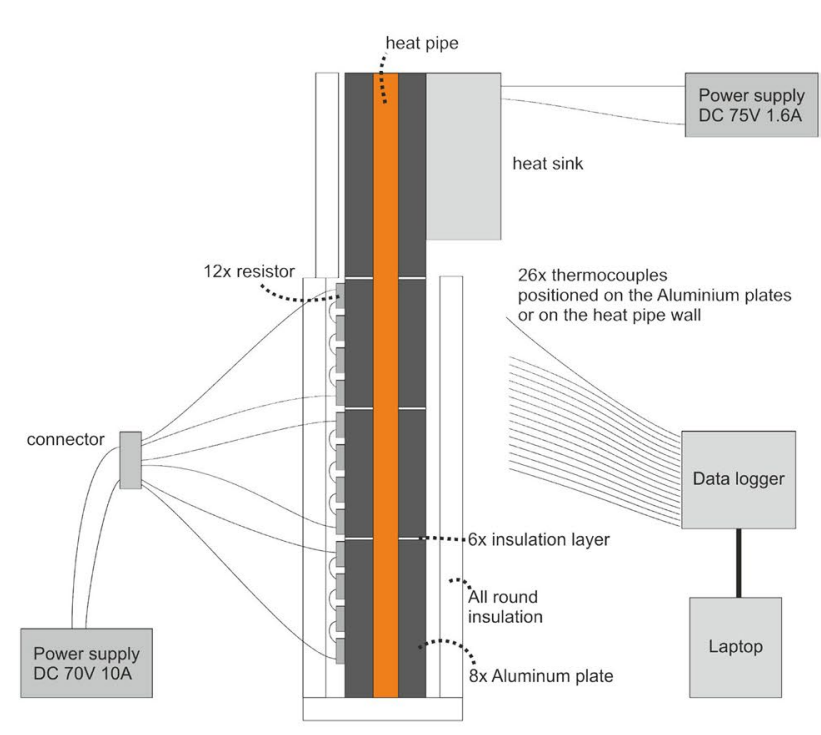

(a)

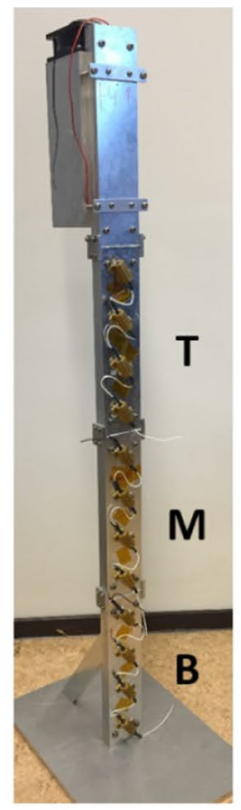

(b)

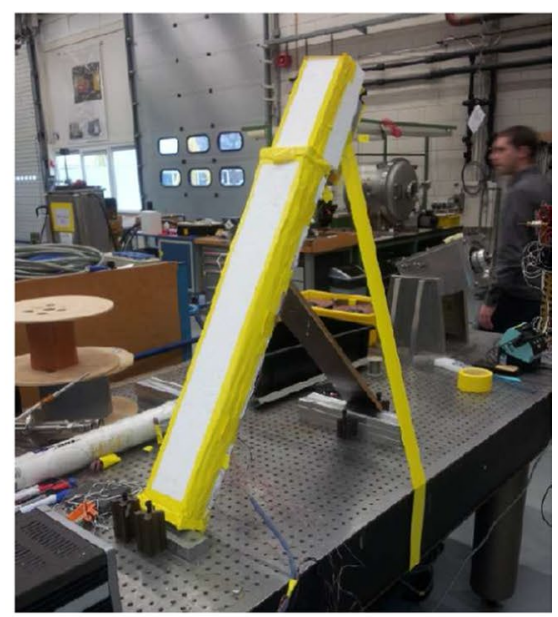

(c)

Fig. 3 Experimental setup consisting of a $1 \mathrm{~m}$ long heat pipe $(\varnothing 12 \mathrm{~mm})$ sandwiched between aluminium plates. a Schematic overview, b prototype, $\mathbf{c}$ measurement set-up

operate best in an evaporator-down mode, the constructed prototype, shown in Fig. 3b, operated with top cooling through a fan-based heat sink. The heat sink was calibrated separately and has a thermal resistance value of $0.14 \mathrm{~K} / \mathrm{W}$.

To generate heat 12 power resistors (each $10 \Omega, 25 \mathrm{~W}$ ) are mounted on the evaporator section. Per section, four resistors are put in series. The three sections are powered in parallel through the power supply $(70 \mathrm{~V}, 10 \mathrm{~A})$.

26 thermocouples (type T, $43 \mu \mathrm{V} / \mathrm{K}$ ) were mounted on the test rig: 12 were used to measure the heat pipe wall temperature, another 12 measured the outside temperature of the aluminium plates and 2 measured the temperature of the in- and out-flowing air through the heat sink. The exact thermocouples locations and numbering are shown in Fig. 4.

During experimental testing the entire heat pipe assembly was insulated, as shown in Fig. 3c, using $3 \mathrm{~cm}$ thick Polystyrene to minimize (convective) heat losses to the environment.

\section{Experimental results}

To guarantee successful heat pipe functioning in operation and to validate the thermal model, a number of scenarios is determined and experimental data was gathered. In total seven configurations, alternating the heating of the bottom (B), middle (M) and top (T) sections of the evaporator are considered. Three of the seven possible heating configurations, namely $\mathrm{B}, \mathrm{BM}$ and $\mathrm{BMT}$ are illustrated in Fig. 5a.

Also four different orientations angles were considered, namely $0^{\circ}$ (horizontal), $30^{\circ}, 60^{\circ}$ and $90^{\circ}$ (vertical, evaporator-down), as illustrated in Fig. 5b. In the horizontal orientation, gravity has no influence on the heat pipe performance. For the other orientations, gravity must be considered. In those cases, the heat pipe operates in an evaporator-down modus, in which bottom heating, as shown in Fig. 5b, is considered.

The maximum heat pipe performance was tested by increasing the heat load with increments of $20 \mathrm{~W}$ for the majority of heating configurations and orientations. When a steady state temperature was recorded, the input power was increased. Steady state was defined as less than $0.5 \mathrm{~K}$ temperature variance per minute. The measurement was ended when the maximum operating temperature of $100{ }^{\circ} \mathrm{C}$ was reached or when the maximum allowable power, set at $80 \mathrm{~W}$ per section and $200 \mathrm{~W}$ in total, was reached.

The maximum steady state heat load per configuration and orientation are presented in Table 1. As expected for the horizontal orientation relative low performance was attained, although by shortening the heat pipe's active region (i.e. moving from configuration $\mathrm{B}$ to $\mathrm{T}$ ) some performance gain was possible. The heat pipe could not be tested up to the power limit and dry-out occurred between 20 and $80 \mathrm{~W}$ depending on the heating configuration. 


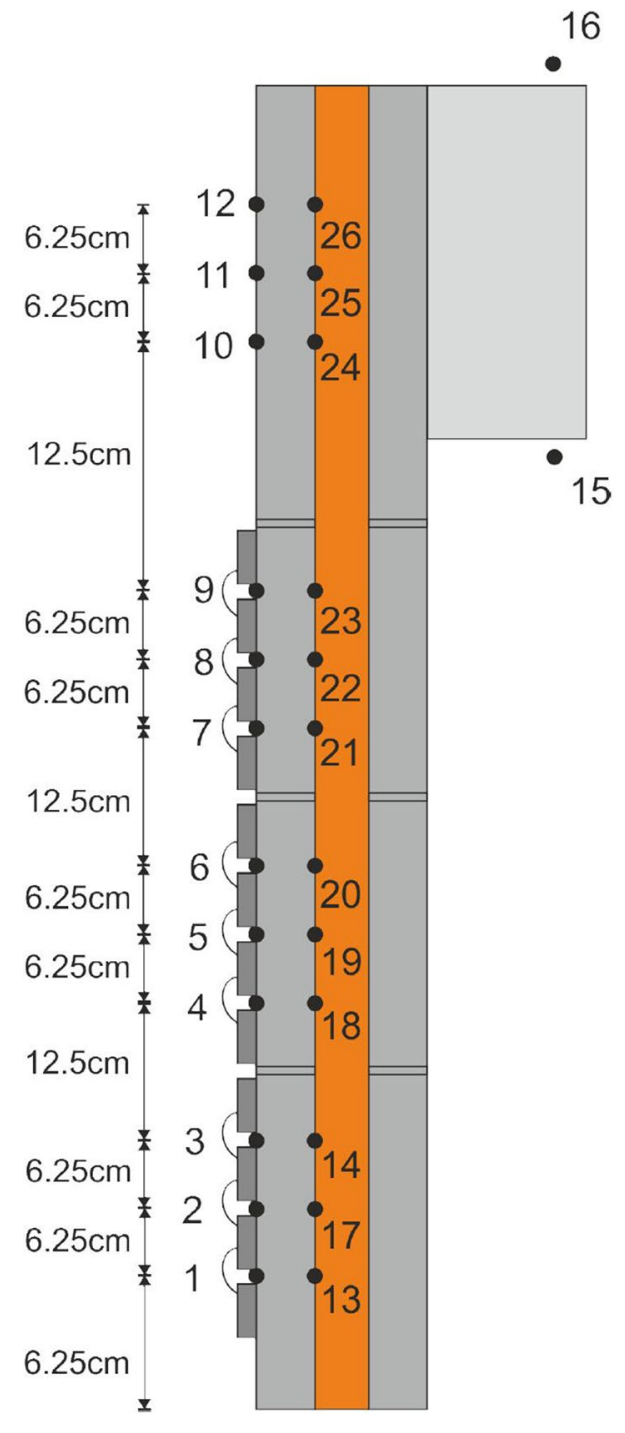

Fig. 4 Thermocouple location and numbering

For all orientations above $30^{\circ}$, the heat pipe could be tested up to the power limit. Evaporator dry-out or other heat pipe limits could not be reached and the heat pipe temperature remained below $85{ }^{\circ} \mathrm{C}$ at all times. This confirms the heat pipe selection procedure of Sect. 2.1.

To check for possible heat losses through the bottom plate, shown in Fig. 3b, the first four and last heating configuration (i.e. B, M, T, BM and BMT) at a $90^{\circ}$ orientation were repeated without the bottom plate connected to the system. The results were identical to the results of Table 1. To check for environmental disturbances the heat pipe was also testing in a climate chamber in which the ambient temperature was varied from 0 to $50{ }^{\circ} \mathrm{C}$. The temperature gradient across the heat pipe decrease just $2 \mathrm{~K}$ for the $50 \mathrm{~K}$ ambient increase. This decrease can be attributed to the improved thermodynamic working fluid properties at the higher temperature.
Additional tests were also performed to quantify heat losses through the insulation layer and electric wiring. The former was determined by also measuring the temperature outside the insulation, while the latter was determined by registering the voltage and current. Overall losses were determined to be between 4 and $9 \%$ of the input power and were therefore not neglected. Hence, in the following analyses the input power for the heat pipe is determined by subtracting the heat losses from the input power of the power supply.

\subsection{Thermal resistances}

Using the thermocouple measurements and the heat pipe power input, the total thermal resistance across the heat pipe can be determined (Eq. 1). To compute the thermal resistance, first the temperature readings for each section (e.g. evaporator, condenser) were averaged. Figure 6 present the results for a vertically oriented heat pipe for 5 heating configurations. The error bars indicate the thermocouple accuracy of $1 \mathrm{~K}$. At low power input, the error bars tend to be relatively large due to the low thermal gradients. For all heating sections active, i.e. the BMT configuration, and a power input of $150 \mathrm{~W}$, the overall thermal resistance was $0.014 \mathrm{~K} / \mathrm{W}$. In this case, the temperature gradient across the heat pipe was $2.1 \mathrm{~K}$ and the average operating temperature was $50.7^{\circ} \mathrm{C}$.

Two clear observations from the figure are that (1) by increasing the evaporator area (i.e. more active sections) the overall thermal resistance drops and (2) by increasing the power input also the overall thermal resistance drops.

The results for the BM and BMT configurations are almost identical. The performance of the single active sections (i.e. B, M and T) is relatively poor. The order of the top, middle and bottom configuration is explained by the fact that the heat pipe is oriented vertically and the working fluid tends to be at the lowest point. This demonstrates that for any configuration is it important for the overall thermal performance that the bottom section is active.

In Fig. 7, the influence on the heat pipe orientation is presented. The figure shows that at a higher input power the results for the $30^{\circ}$ and $60^{\circ}$ inclination angles are similar, and worse than for the $90^{\circ}$ orientation. The figure also shows the aforementioned non-experienced heat losses through the bottom plate, as both results for the $90^{\circ}$ inclination angle are identical. The results for the $0^{\circ}$ inclination angle are not depicted, as the heat pipe did not operate well at this angle. The temperature gradient across the heat pipe rose above $25 \mathrm{~K}$. A distinctive order between the $30^{\circ}, 60^{\circ}$ and $90^{\circ}$ angles was not observed; also, not in the other heating configurations. No clear explanation for this effect could be found. 


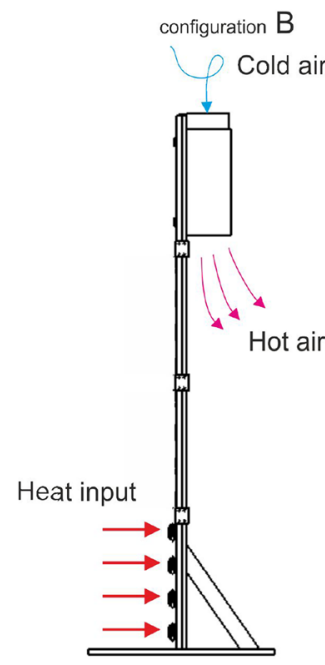
determined maximum heat load (W) for various heating configurations and orientations

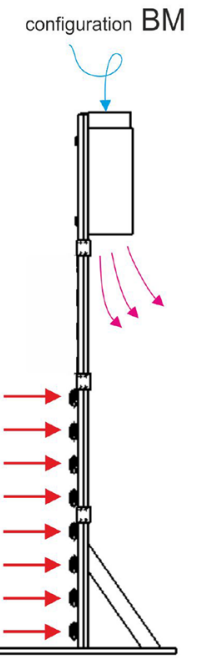

(a)
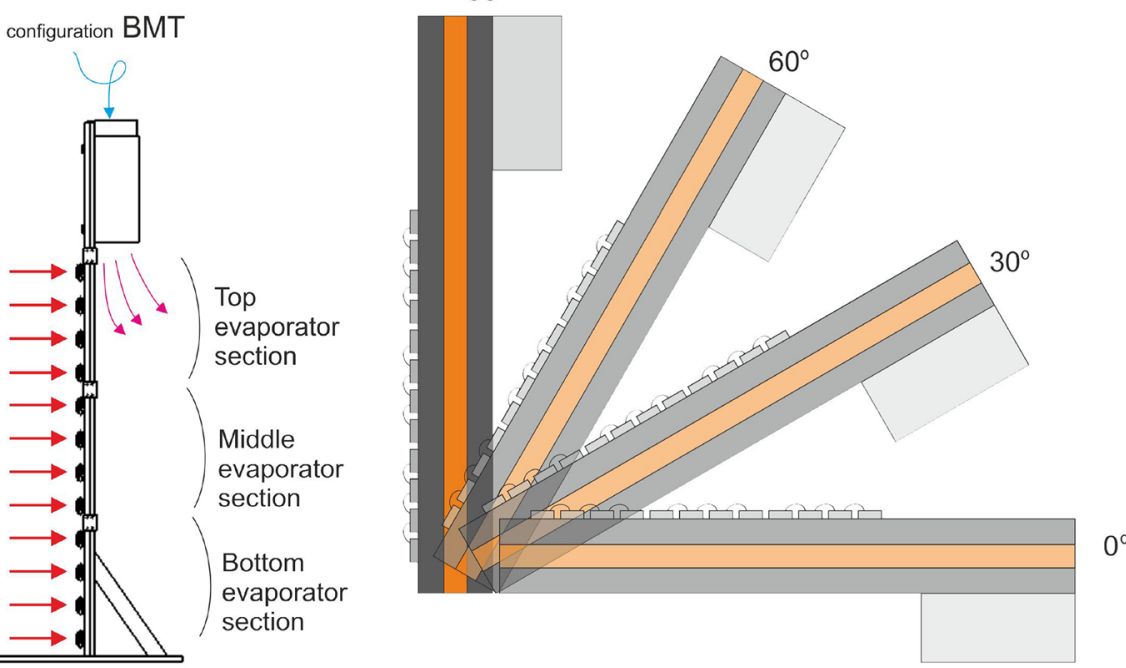

(b)

Fig. 5 Configuration of three heating modes and four heat pipe orientations

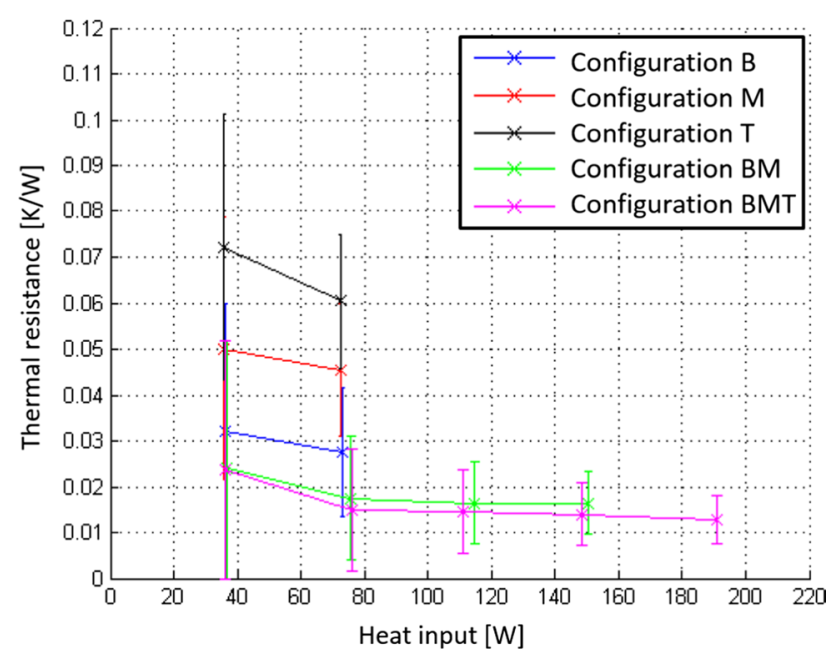

Fig. 6 Thermal resistance values for a vertically oriented $\left(\varphi=90^{\circ}\right)$ heat pipe for 5 heating configurations

\subsection{Heat pipe start-up behaviour}

For the intended application and for all heating configurations, heat pipe start-up without excessive temperature

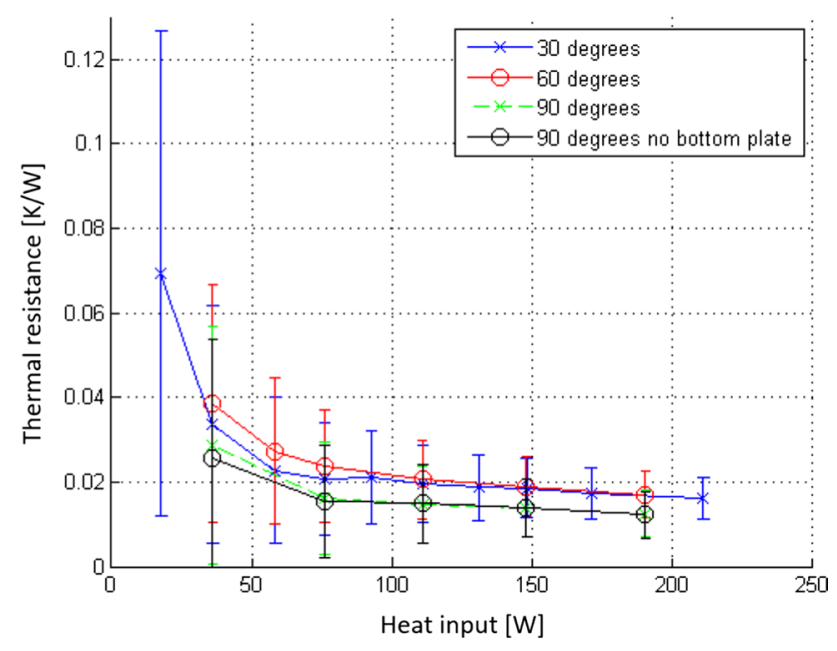

Fig. 7 Thermal resistance values for the BMT heating configuration for various heat pipe orientations

overshoot must be guaranteed. Especially for the vertical orientation, and $\mathrm{M}, \mathrm{T}$ and MT heating configurations (i.e. no bottom heating), this must be assured. For these configurations, without power the working fluid may 
accumulate at the bottom and the wick's capillary performance may be insufficient to draw working fluid to the upper sections. Hence, to validate heat pipe start-up, rather than incrementing the input power, the power was switched on for each experiment while the heat pipe was at rest and at ambient temperature [17], thus mimicking the power-up of an actual system.

For heating configuration $\mathrm{T}$, in which the powered section is furthest away from the bottom, the worst performance is expected. The transient start-up behaviour for this configuration at $40 \mathrm{~W}$ input power is shown in Fig. 8. The thermocouple locations and numbers correspond to Fig. 4. The top section, Thermocouples 7-9, indeed shows a relatively large temperature overshoot. The highest measured temperature value was $74{ }^{\circ} \mathrm{C}$ for heating configuration $\mathrm{T}$ and $80 \mathrm{~W}$ input power (not shown), which is acceptable for the intended application. Also, visible in the figure is the delay time before the middle and bottom sections, and the condenser start to heat up, due to the thermal mass of each section. In fact, this is even noticeable within a single section.

The cycle period in this case is a little over $1 \mathrm{~h}$. After that, a second cycle starts; however, the overshoot is diminished by around $57 \%$ indicating a critically damped system. The cycle period lengthens by almost $10 \mathrm{~min}$. For the $\mathrm{M}$ and MT configurations the first cycle period is much shorter, around $15 \mathrm{~min}$., and the second period lengthens by about $5 \mathrm{~min}$. The shorter cycle periods can be explained by the fact that the conducting path the heat needs to travel towards the liquid pool at the bottom is much shorter. It was also observed that the input power has no significant effect on the cycle period. Naturally, the peak temperatures of the oscillations are higher. The offset between the peak temperatures that constitute one oscillation scale approximately proportional to the input power. The largest time to reach steady state was for heating configuration $\mathrm{T}$ at $80 \mathrm{~W}$ and took more than $4 \mathrm{~h}$.

The physical phenomena occurring during start-up for non-bottom heating configurations are believed to be as follows. First, as the working fluid resides at the bottom of the heat pipe, the heat pipe operates in conduction mode and no two-phase transport occurs. This can be seen from Fig. 9, in which the temperature distribution across the heat pipe is shown at the time instance of the first temperature peak for heating configuration $\mathrm{M}$ indicated by the red bars. Both the temperature gradient of Thermocouples 1-3 and 4-6 are linear indicating conduction. The jump between the bottom and middle section is caused by the thermal insulation.

Second, a first batch of working fluid is brought into the top section of the heat pipe and the two-phase cycle is started. Heat that finally reaches the working fluid at the bottom will start the evaporation process. At the peak temperature of the first oscillation, the average temperature of the evaporator (bottom) and condenser sections

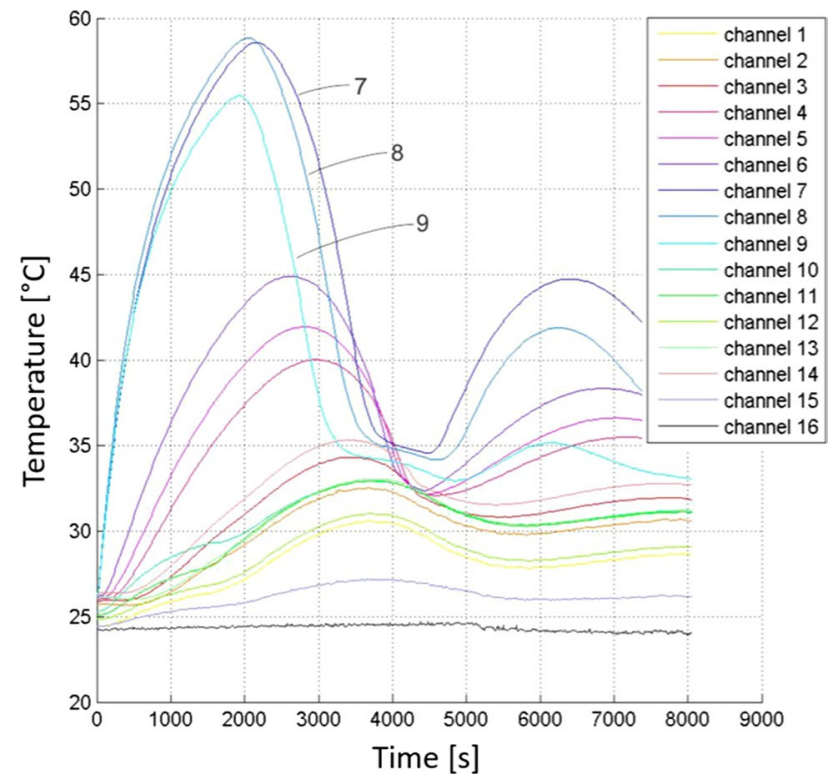

Fig. 8 Transient start-up for heating configuration T; heat pipe is oriented vertically $\left(\varphi=90^{\circ}\right)$ at $40 \mathrm{~W}$ input power

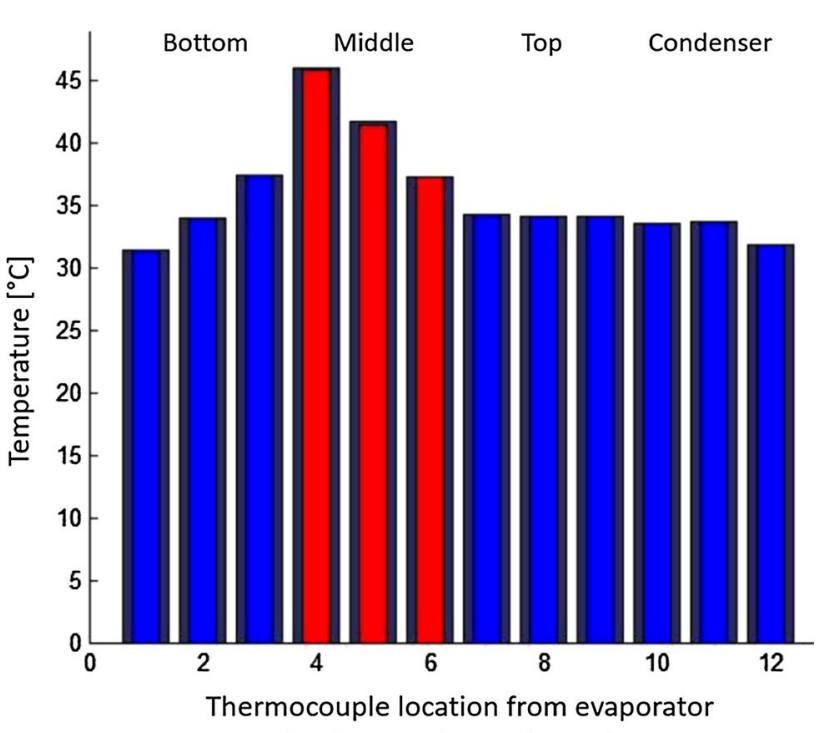

(1-9) to condenser (10-12)

Fig. 9 Temperature distribution for configuration $\mathrm{M}$; heat pipe is oriented vertically $\left(\varphi=90^{\circ}\right)$ at $80 \mathrm{~W}$ input power

were 34.4 and $33.1{ }^{\circ} \mathrm{C}$, respectively. This average temperature difference was enough the start the two-phase cycle and vapour starts to travel upwards to the condenser, where it condenses. The condensate return downwards, but the heated section will cause the working fluid to reevaporate. This leads to the temperature decline of the heated section and end the first cycle period. Hence, now the top section of the heat pipe operates in two-phase mode. 
Third, since there is a mismatch between the power transport capacity of the heat pipe in two-phase mode and the input power, the heated section will start to heat up again, causing a second temperature peak.

Fourth, a similar yet smaller batch of working fluid is brought into the two-phase cycle. This cyclic behaviour continuous until sufficient working fluid is brought upwards to match the continuous power input and explains the oscillating start-up behaviour observed from Fig. 8.

For configurations where the bottom section is active, this dynamic start-up behaviour does not occur since from the start working fluid is brought into a two-phase cycle.

\section{Thermal model validation}

The comparison between the thermal model and the experimental results are shown in Fig. 10 for the BMT configuration at $30^{\circ}$ orientation angle. The experimental results are consistently higher than the modelled results indicating that not all physical effects are (fully) captured correctly. The modelled results are however always within the error bars.

At lower power inputs, the thermal model deviates progressively. This is likely caused by the fact that at lower power input the effective condenser length decreases. The model does not account for this since it uses a fixed condenser section length. For an input power of $75 \mathrm{~W}$ and higher, the large decline in the measured overall thermal resistance stops, indicating that the maximum effective condenser length is reached. The slight decline occurring after this threshold can be explained by the elevated temperatures and thereby improving thermodynamic working fluid properties.

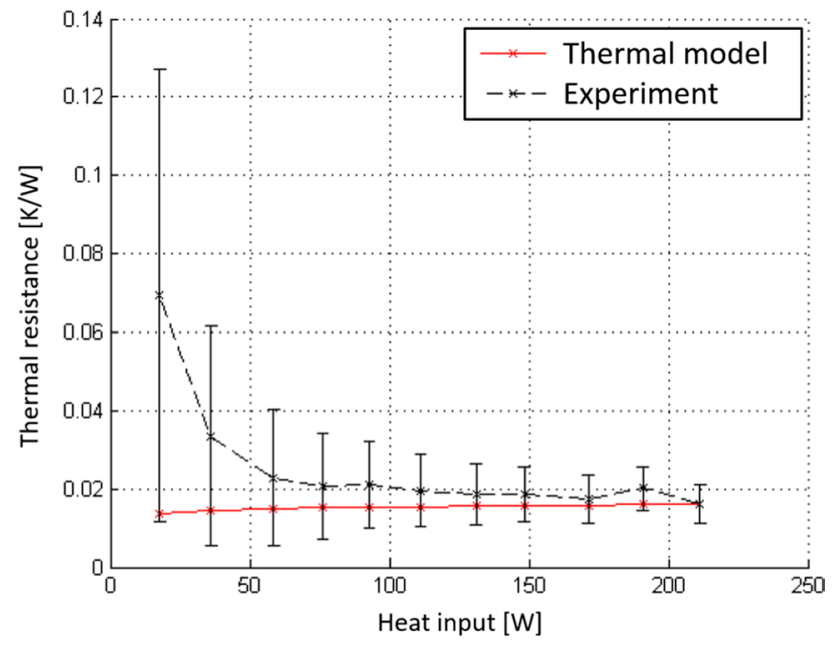

Fig. 10 Overall heat pipe thermal resistance results for the BMT configuration at $30^{\circ}$ orientation angle
The deviation of the condenser wall temperature between the model and experimental results (not depicted) varies between 0.5 and $0.9 \mathrm{~K}$ for all power inputs, in which the experimental results are consistently higher. This indicates that the fan and heat sink thermal resistances are properly calibrated.

To gain more insight into the contribution of the individual heat pipe parts towards the overall thermal resistance, Fig. 11 shows the breakdown of resistances as a function of the input power. The largest contribution according to the model is the resistance of the condenser section. Wall conduction and the evaporator section contribute almost equally but less; they are also independent of the input power. Finally, the impact of vapour pressure losses are insignificant at higher power inputs, demonstrating the effectiveness of heat pipes. The predicted overall thermal resistance can be considered accurate enough for $75 \mathrm{~W}$ of input power and higher. Other modelling approaches as e.g. Kim et al. [18], and Khrustalev and Faghri [19] suggest to use the local film thickness to predict the condenser heat transfer coefficient. Compared to the film-wise condensation model of Eq. (3), these models also under predict the thermal resistance however by a larger factor, namely a factor 10. To tune the model for lower input powers, an empirical approach should be considered, because the underlying modelling parameters as condenser length and film thickness are difficult to predict for low power inputs.

\section{Planar cooling application}

For the intended planar cooling application, the principle idea is to use an array of relatively long heat pipes, whereby heat is dispose through a long evaporator section.

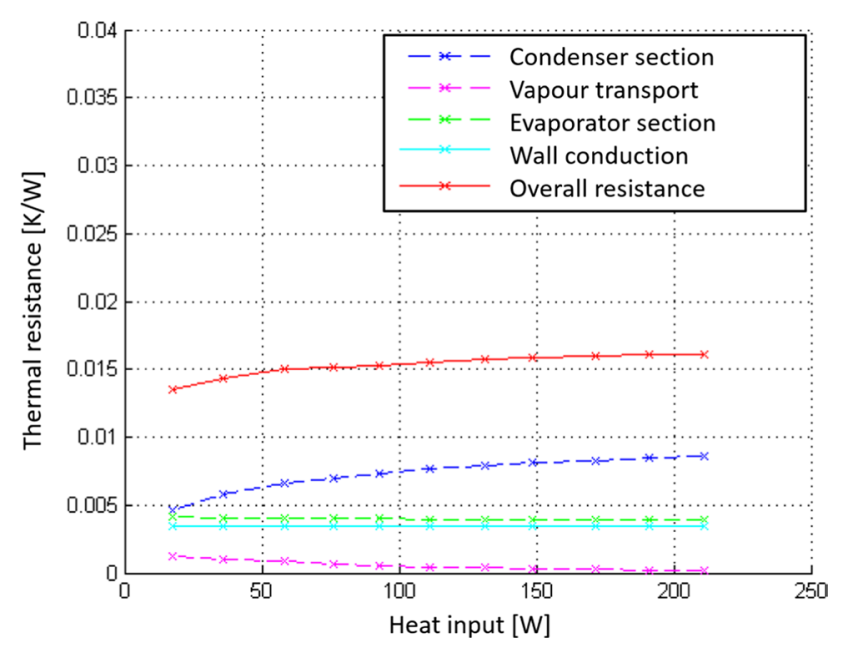

Fig. 11 Contribution of thermal resistances within the thermal model (BMT configuration at $30^{\circ}$ angle) 
The measured performances and overall thermal resistances are used to design a system-level electronics cooling infrastructure for an AESA, whereby the temperature uniformity across the panel is an important design criterion. The total input power is specified at $1 \mathrm{~kW}$ with a planar heat flux well over $5.5 \mathrm{~kW} / \mathrm{m}^{2}$. The maximum planar temperature is set at $100{ }^{\circ} \mathrm{C}$ at the footprint of the electronic components for an ambient temperature of $20^{\circ} \mathrm{C}$. According to the estimated heat pipe limitations of Fig. 1 and the experimental results of Sect. 4, the single heat pipe is able to transport $200 \mathrm{~W}$ of input power for all orientations except horizontal and for all heating configurations. Based on this assessment a minimum of five heat pipes is required to transport a heat load of $1 \mathrm{~kW}$.

The final concept design consists of six heat pipes positioned next to each other as shown in Fig. 12. It was decided to use six heat pipes to have a symmetrical layout

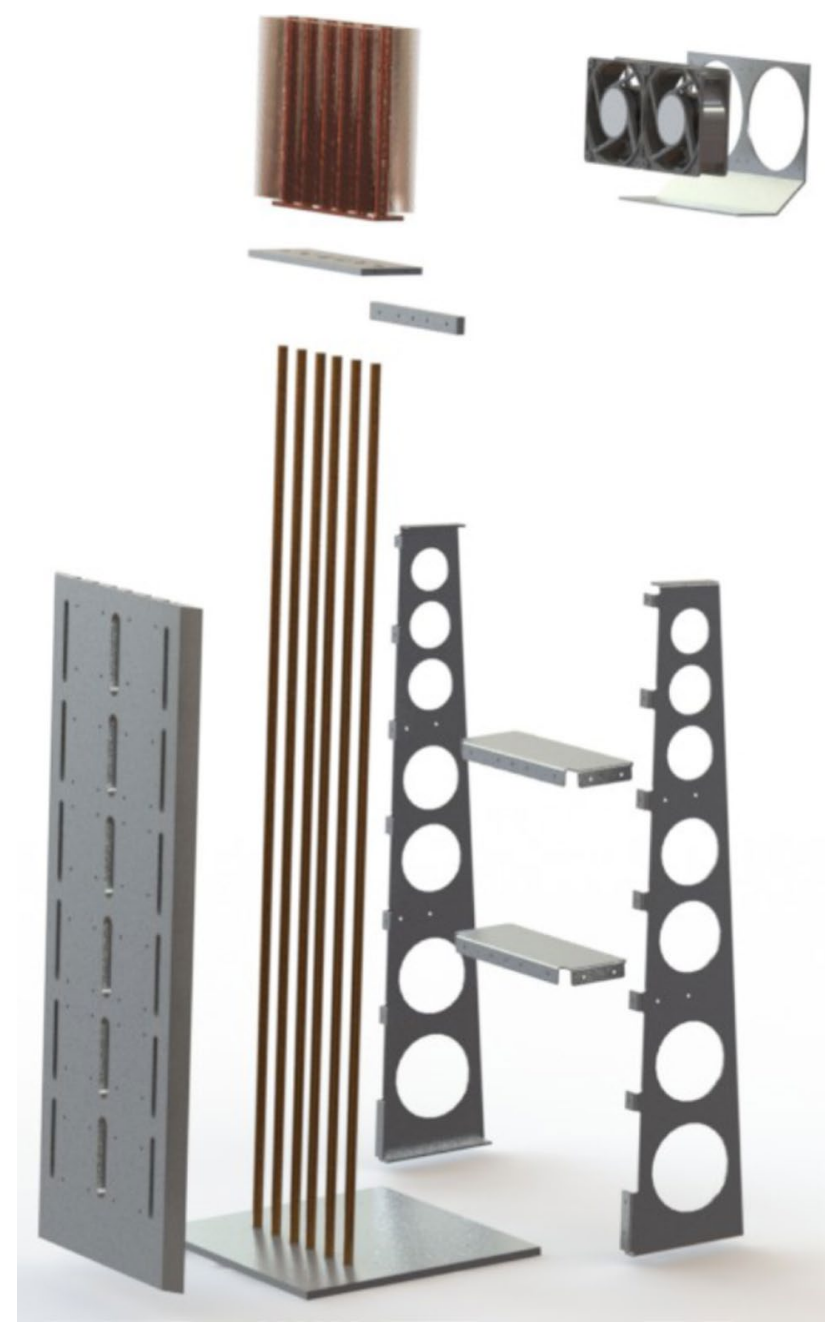

Fig. 12 Exploded view of the final design featuring six $1 \mathrm{~m}$ heat pipes in parallel having a long $(\sim 75 \%)$ evaporator section and external fan-based top cooling
Table 2 Thermal resistance model and temperature prediction of the final concept

\begin{tabular}{llll}
\hline Nodal location & $\begin{array}{l}\text { Interface } \\
\text { component }\end{array}$ & $\begin{array}{l}\text { Resistance } \\
(\mathrm{K} / \mathrm{W})\end{array}$ & $\begin{array}{l}\text { Temperature } \\
\left({ }^{\circ} \mathrm{C}\right)\end{array}$ \\
\hline Ambient air & Heat sink & 0.043 & 20 \\
Heat pipe condenser & Heat pipe & $0.020^{\mathrm{a}}$ & 63 \\
Heat pipe evaporator & Planar interface & 0.0071 & 66 \\
Electronics component & & & 73 \\
\hline
\end{tabular}

a The heat pipe thermal resistance is specified per heat pipe

and redundancy. Using the thermal model and the experimental results, the maximum planar temperature was estimated at $73{ }^{\circ} \mathrm{C}$ well below the specified maximum. The predicted temperatures are listed in Table 2. The largest temperature gradient is found at the heat output side, i.e. from the condenser sections to the air-cooled heat sink, namely $43 \mathrm{~K}$. Note that the thermal resistance of the heat sink is lower than the heat sink used for the experimental validation. This design improvement can be seen by comparing Figs. $3 \mathrm{~b}$ and 12, and involves much less conduction of heat. The thermal resistance of a single heat pipe was set at $0.02 \mathrm{~K} / \mathrm{W}$ as a worst-case scenario from Figs. 6 and 7 . In this case, the estimated temperature gradient across the heat pipes is $3.3 \mathrm{~K}$. Note that for this estimate the total heat load is divided over the six heat pipes. This low temperature gradient is instrumental to reaching a high temperature uniformity across the planar structure.

\section{Conclusions}

The paper present a planar cooling strategy using relatively long heat pipes. Planar cooling is achieved by having a long evaporator section up to $75 \%$. Modelling results using conventional heat pipe limitations, a thermal resistance network and experimental results have been presented. The thermal model and experiments compare relatively well, especially for higher input powers.

Multiple heating configurations and orientation angles have been tested experimentally. The performance of the single active sections (i.e. $\mathrm{B}, \mathrm{M}$ and $\mathrm{T}$ ) is relatively poor compared to having multiple active heating sections. The results for the BM and BMT configurations are almost identical and show an overall thermal resistance below $0.02 \mathrm{~K} / \mathrm{W}$ at power inputs above $75 \mathrm{~W}$. For inclination angles of $30^{\circ}$ and $60^{\circ}$, the thermal performances are similar. The performance vertically in evaporator-down mode 
$\left(\varphi=90^{\circ}\right)$ is better. Horizontally $\left(\varphi=0^{\circ}\right)$ the heat pipe did not operate well, as expected, causing a high temperature gradient.

Dynamic start-up phenomena in the cases where no bottom heating is applied have been observed and clarified. Following the four-step clarification, a critically damped system can be assumed as long as the heat pipe is not operated beyond its limit. The largest cycle period was a little over one hour and depends on the heating configuration. The highest measured temperature value was $74{ }^{\circ} \mathrm{C}$ for the top heating configuration and $80 \mathrm{~W}$ input power. In future work, the dynamic start-up phenomena can be modelled by observing the peak temperature values from sets of measurement data and computing a corresponding damping coefficient.

Finally, for the intended planar cooling application, a system-level concept design that uses six heat pipes in a parallel configuration has been presented. A high temperature uniformity can be achieved across the planar structure, due to the low thermal gradient across the heat pipes. $1 \mathrm{~kW}$ of heat load can be dissipated to an ambient air temperature of $20^{\circ} \mathrm{C}$, in which the maximum temperature locally at the electronics components is $73{ }^{\circ} \mathrm{C}$ and remains well below the critical temperature.

Acknowledgements The authors sincerely thank Koen Grobben and Marc Schreiber for their work both on the modelling and experimental results. Funding to publish this work Open Access was provided by VSNU Vereniging van Universiteiten.

Open Access This article is distributed under the terms of the Creative Commons Attribution 4.0 International License (http://creativecommons.org/licenses/by/4.0/), which permits unrestricted use, distribution, and reproduction in any medium, provided you give appropriate credit to the original author(s) and the source, provide a link to the Creative Commons license, and indicate if changes were made.

\section{References}

1. Faghri A (2014) Heat pipes: review, opportunities and challenges. Front Heat Pipes. doi:10.5098/fhp.5.1
2. Dunn PD, Reay D (2012) Heat pipes. Elsevier, Amsterdam

3. Faghri A (1995) Heat pipe science and technology. Taylor \& Francis, London

4. Wits WW, Mannak JH, Legtenberg R (2007) Planar heat pipe for cooling. Thales Nederlands B.V., Huizen

5. Wits WW, Kok JBW (2011) Modeling and validating the transient behavior of flat miniature heat pipes manufactured in multilayer printed circuit board technology. J Heat Transf Trans ASME. doi:10.1115/1.4003709

6. Lin K-T, Wong S-C (2013) Performance degradation of flattened heat pipes. Appl Therm Eng 50:46-54

7. Semenov S (2009) Lightweight planar heat pipe for fuel cell cooling. In: 7th international energy conversion engineering conference. American Institute of Aeronautics and Astronautics

8. Dillig M, Meyer T, Karl J (2015) Integration of planar heat pipes to solid oxide cell short stacks. Fuel Cells 15:742-748. doi:10.1002/fuce.201400198

9. Schreiber M, Wits WW, te Riele GJ (2016) Numerical and experimental investigation of a counter-current two-phase thermosyphon with cascading pools. Appl Therm Eng. doi:10.1016/j. applthermaleng.2015.12.095

10. Boukhanouf R, Haddad A, North M, Buffone C (2006) Experimental investigation of a flat plate heat pipe performance using IR thermal imaging camera. Appl Therm Eng 26:2148-2156

11. Chi SW (1976) Heat pipe theory and practice: a sourcebook. Hemisphere Pub. Corp, Washington, DC

12. Tien CL, Chung KS (1979) Entrainment limits in heat pipes. AIAA J 17:643-646. doi:10.2514/3.61190

13. Cao Y, Faghri A, Mahefkey ET (1993) Micro/miniature heat pipes and operating limitations. American Society of Mechanical Engineers, Heat Transfer Division, (Publication) HTD, pp 55-62

14. Reay DA, Kew PA, McGlen R, Dunn PD (2014) Heat pipes: theory, design, and applications

15. Asselman GAA, Green DB (1973) Heat pipes. Philips Tech Rev 16:169-186

16. Çengel YA, Ghajar AJ (2011) Heat and mass transfer: fundamentals and applications. McGraw-Hill, New York

17. Cotter TP (1967) Heat pipe startup dynamics. In: Thermionic conversion specialist meeting, USAEC Report CONF-671045-4, pp 344-348

18. Kim SJ, Ki Seo J, Hyung Do K (2003) Analytical and experimental investigation on the operational characteristics and the thermal optimization of a miniature heat pipe with a grooved wick structure. Int J Heat Mass Transf 46:2051-2063. doi:10.1016/S0017-9310(02)00504-5

19. Khrustalev D, Faghri A (1994) Thermal analysis of a micro heat pipe. J Heat Transfer 116:189-198. doi:10.1115/1.2910855 